\title{
The Relation between Interstitial Lung Disease and Chronic HCV Infection
}

\author{
El Saed G El Badrawy, Taghrid Mohamed Abdalla \\ and Hanan Mohammed El Shahat* \\ Tropical Medicine and Chest Departments*, \\ Faculty of Medicine, Zagazig University,Egypt
}

Corresponding Author Taghrid Mohamed Abdalla

Mobile:

$+201014616211$

E mail:

tagkomy@gmail.com

Key words: Interstitial, fibrosis, inflammation, HRCT, hepatitis intrahepatic, extrahepatic
Background and study aim: Interstitial lung disease (ILD) includes a variety group of about 200 conditions that insult the lung parenchyma with different patterns of inflammation and fibrosis. Hepatitis C virus (HCV)is Flavivirus with diverse hepatic and extrahepatic diseases. Its direct and indirect pathogenic association with many pulmonary manifestations-including interstitial lung disease-has been suggested yet needs more elucidation.

Patients and Methods: A case control study was conducted with a total of 50 chronic hepatic patients. They were equally divided into two groups, HCV positive group (group $1=25$ patients) and $\mathrm{HCV}$ negative group (group $2=25$ patients). Group 1 was subdivided into two subgroups, without-idiopathic interstitial pneumonias patients) and with idiopathic interstitial pneumonias patients (IIPs subgroup $B=12$ patients). Both groups were subjected to thorough history taking, clinical examination, and routine investigations. The diagnosis of $\mathrm{HCV}$ was confirmed by viral markers patients (without IIPs subgroup $A=13$

including $\mathrm{HCV}$ antibodies and PCR. Other chronic hepatic liver diseases were confirmed by abdominal ultrasound and ultrasound- guided liver biopsy. Arterial blood gases, auto antibodies, Computerized pulmonary function tests and radiological studies including plain $\mathrm{X}$ ray chest and heart and HRCT scanning were also done. All patients with idiopathic pulmonary fibrosis (IPF) had fulfilled the ATS/ ERS diagnostic guidelines. Both groups were matched according to age, sex and body mass index.

Results: The HCV positive group was found to have a significantly higher frequency of ILD than the HCV negative group with also more restrictive pattern hypoxemia and higher scores of IPF (by computed tomography).

Conclusion: ILD is more frequent in patients with chronic HCV infection with higher grades of fibrosis and hypoxemia. $\mathrm{HCV}$ infection may be predisposing factor for IPF.

\section{INTRODUCTION}

Hepatitis C virus (HCV) is a hepatotropic and lymphotropic virus that belongs to the Flaviviridae family. Chronic HCV infection is associated with a wide spectrum of clinical hepatic and extrahepatic disease including nonHodgkin's lymphoma, mixed cryoglobulinemia, nephrological, dermatological, cardiovascular, neurological and pulmonary disorders [1-3]. Multiple direct and indirect pulmonary manifestations were associated with chronic $\mathrm{HCV}$ infection. Direct manifestations include precipitation or deterioration of bronchial asthma [4,5] and COPD
[6], pulmonary fibrosis and interstitial pneumonitis [7-10]. Indirect effects are related to liver cirrhosis and its complications including Porto pulmonary hypertension [11], hepatopulmonary syndrome [12], mixed cryoglobulinemia [13], and nonHodgkin's B-cell lymphomas [14].

Interstitial lung disease (diffuse parenchymal lung disease) is a group of multiple conditions insulting the lung parenchyma [15]. These conditions present with different grades of interstitial inflammation and fibrosis and consequently different clinical, radiological and histopathological 
manifestations. No etiological factors can be decided in about two-thirds of ILD cases. However, the remainder are suggested to be associated with infections, drugs, autoimmunity, environmental exposure, or genetic involvement [16]. Epidemiological data about ILD is lacking all over the world especially from developing countries. Moreover, these data can be inaccurate in some countries because of the high prevalence of tuberculosis with fibrosis that can be mistaken for ILD. The diagnosis of ILD requires clinical evaluation by an expert pulmonologist, thorough radiological assessment, and expert histopathological evaluation [17].

Chronic HCV infection was suspected for a long time to be involved in the pathogenesis of ILD by inducing chronic inflammation and fibrosis in the lung similar to those induced in the liver [18]. For epidemiological purposes, the American Thoracic Society/ European Respiratory Society (ATS/ ERS) established a practical and etiological classification of ILD. Since the parenchyma of the lung is the primary site of insult, the term ILD was changed to diffuse parenchymatous lung disease (DPLD) that was classified into; DPLD of known origin, Idiopathic interstitial pneumonias (IIPs), Granulomatous diseases, and other forms of DPLD [19,20]. The DPLD of known origin was found to be associated with causative agents such as drugs or cardiovascular diseases, connective tissue diseases, and environmental or occupational exposures. Granulomatous diseases usually manifest as sarcoidosis. Other rare forms of DPLD include lymphangioleiomyomatosis, pulmonary Langerhans cell histiocytosis, pulmonary alveolar proteinosis, and eosinophilic pneumonia.

\section{PATIENTS AND METHODS}

The study was conducted in Tropical Medicine and Chest Departments, Zagazig University Hospitals between May 2015 and May 2016.The study protocol was approved from the Ethical Committee of the university. A case control study was conducted with a total of 50 chronic hepatic patients. They were equally divided into two groups, $\mathrm{HCV}$ positive group (group $1=25$ patients) and HCV negative group (group $2=25$ patients). Group 1 was subdivided into two subgroups, without-idiopathic interstitial pneumonias patients (without IIPs subgroup $A=13$ patients) and with idiopathic interstitial pneumonias patients (with IIPs subgroup $B=12$ patients). Group 2 included patients with autoimmune hepatitis, hepatitis $\mathrm{B}$ virus infection (HBV) and non-alcoholic steatohepatitis (NASH).

\section{Exclusion criteria:}

- Patients with history of interferon therapy.

- Patients with chronic pulmonary diseases other than ILD.

- Patients with environmental exposures (such as drugs, smoking, granulomatous diseases and collagen vascular diseases).

- Patients with history of malignancy.

- Patients less than 20 years or more than 70 years.

- Patients with comorbid diseases such as collagen disorders and immune deficiency disorders.

All patients were subjected to the following:

- Thorough history taking, clinical examination with special emphasize on hepatic and respiratory diseases.

- Laboratory investigations included complete blood count, liver function tests, diagnosis of $\mathrm{HCV}$ infection, arterial blood gases, diagnosis of HBV infection, serum creatinine and investigations of autoantibodies. HCV infection was diagnosed by a third-generation enzyme linked- immunosorbent assay (ELISA) test (OrthoDiagnosis System, Raritan, New Jersey, USA). Confirmation of HCV infection was achieved by semi - automated RT- PCR (Cobas Amplicor HCV v 2.0 Roche Molecular system). HBV infection was diagnosed by detection of $\mathrm{HBsAg}, \mathrm{HBc} \mathrm{IgG}$ and PCR.

- Computerized pulmonary function tests including lung volume, forced vital capacity (FVC), forced expiratory volume after one second (FEV 1), FEV 1/ FVC and peak expiratory flow rate (PEF) were measured with standard spirometric technique (Spiro- Jaeger, Germany). The highest values of at least three maneuvers were selected.

- Radiological procedures included abdominal ultrasound, plain $\mathrm{X}$ - ray chest and heart $(\mathrm{P}-\mathrm{V}$ view to visualize reticular opacities, haziness, patchy consolidation, ground glass opacities and nodules) and high resolution computerized tomography (HRCT scanning) using multi detector computed tomography of the chest with a 16 MDCT system (Aquilion 16, TOSHIBA medical system). The following scan protocol was used; helical full rotation $0.5 \mathrm{~s}$, detector configuration of 16-0.625, beam collimation of $10 \mathrm{~mm}$, helical thickness of $0.625 \mathrm{~mm}$, pitch of 23 and a table speed of $23 \mathrm{~mm} /$ rotation. Images were acquired at full inspiration from the lung apex to the base. 
- Ultrasound guided liver biopsy was taken under local anaesthesia. Histopathological examination and classification were done regarding fibrosis based on METAVIR scoring system.

METAVIR scoring system of hepatic fibrosis:

\begin{tabular}{|l|l|}
\hline F0 & No fibrosis. \\
\hline F1 & Mild fibrosis- Portal fibrosis without septa. \\
\hline F2 & $\begin{array}{l}\text { Moderate fibrosis- portal fibrosis and few } \\
\text { septa. }\end{array}$ \\
\hline F3 & $\begin{array}{l}\text { Severe fibrosis- numerous septa without } \\
\text { fibrosis. }\end{array}$ \\
\hline F4 & Cirrhosis. \\
\hline
\end{tabular}

\section{Statistical analysis:}

Data were collected, tabulated and analyzed using SPSS (Statistical package for social science) version 15. Qualitative data were presented as numbers and percent. Chi-square test was used for comparison between groups. Normally presented data were presented as mean +/-SD. Student - $\mathrm{t}$ test was used to compare the two groups. No parametric data was presented such as min - max and median. Mann - Whitney test was used for comparing between groups. $\mathrm{P}$ $<0.05$ was considered statistically significant.

\section{RESULTS}

Fifty hepatic patients were included in this study. They were equally divided into two groups, HCV positive group (group $1=25$ patients) and $\mathrm{HCV}$ negative group (group $2=25$ patients), $\mathrm{HCV}$ negative group were (HBV 12 patients, NASH 6 patients, Autoimmune hepatitis 5 patients, unidentified cause 2patients).

Group 1 was subdivided into two subgroups, without-idiopathic interstitial pneumonias patients (without IIPs subgroup $A=13$ patients) and with idiopathic interstitial pneumonias patients (with IIPs subgroup $B=12$ patients). Both groups were divided into age and sex groups without significant statistical difference.

No significant statistical difference was found between without IIPs and with IIPs groups in HCV positive patients regarding the demographic data.

There were $44 \%$ of $\mathrm{HCV}$ positive cases with low viremia while $56 \%$ showed high viremia.

Table (1): Common respiratory symptoms and signs of HCV positive group

\begin{tabular}{|l|c|c|c|c|c|c|}
\hline \multirow{2}{*}{} & \multicolumn{2}{|c|}{$\begin{array}{c}\text { without IIPs } \\
(\mathbf{N}=\mathbf{1 3})\end{array}$} & \multicolumn{2}{c|}{$\begin{array}{c}\text { With IIPs } \\
(\mathbf{N}=\mathbf{1 2})\end{array}$} & \multirow{2}{*}{$\mathbf{X}^{\mathbf{2}}$} & \multirow{2}{*}{} \\
\cline { 2 - 5 } & $\mathbf{N}$ & $\mathbf{\%}$ & $\mathbf{N o}$ & $\mathbf{\%}$ & & \\
\hline Chest pain & 1 & $7.7 \%$ & 2 & $16.7 \%$ & 0.476 & 0.490 \\
\hline Cough & 2 & $15.4 \%$ & 3 & $25 \%$ & 0.361 & 0.548 \\
\hline Hemoptysis & 0 & $0 \%$ & 1 & $8.3 \%$ & 1.128 & 0.288 \\
\hline Dyspnea & 5 & $38.5 \%$ & 12 & $100 \%$ & 10.860 & $0.001 *$ \\
\hline
\end{tabular}

Table (2): Comparison between the studied groups as regard ABG.

\begin{tabular}{|c|c|c|c|c|c|c|}
\hline & $\mathbf{H C}$ & $\begin{array}{l}\text { gative } \\
25\end{array}$ & HC & $\begin{array}{l}\text { ositive } \\
25\end{array}$ & $\mathbf{X}^{2}$ & $\mathbf{P}$ \\
\hline Normal ABG & 23 & $92 \%$ & 13 & $52 \%$ & \multirow{4}{*}{10.009} & \multirow{4}{*}{$0.007 *$} \\
\hline Mild hypoxemia (60-80 mmHg) & 0 & $0 \%$ & $\overline{0}$ & $0 \%$ & & \\
\hline Moderate hypoxemia $(50-60 \mathrm{mmHg})$ & 2 & $8 \%$ & 11 & $44 \%$ & & \\
\hline Severe hypoxemia $(<49 \mathrm{mmHg})$ & 0 & $0 \%$ & 1 & $4 \%$ & & \\
\hline
\end{tabular}

Table (3): Pattern of Pulmonary functions in HCV negative and HCV positive groups

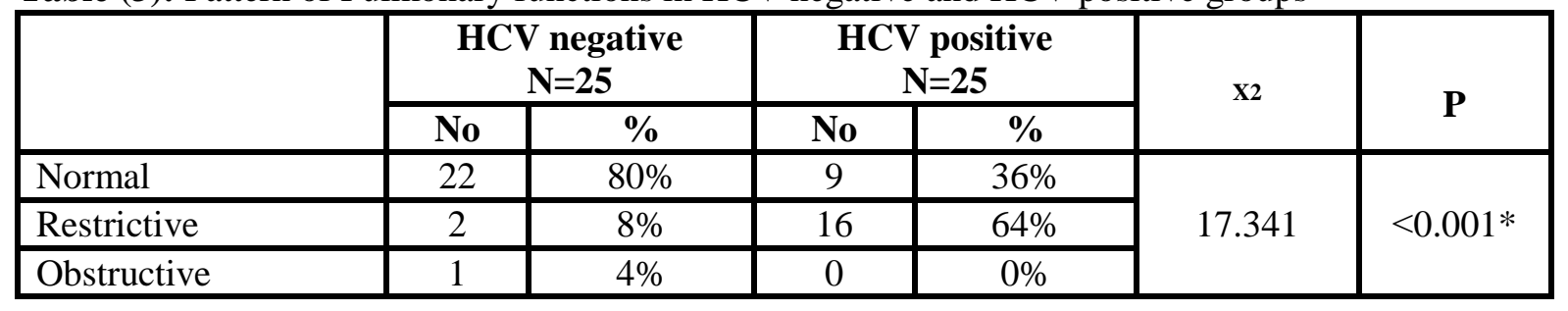


Table (4): Comparison between HCV positive IIPs cases and HCV negative IIPs cases as regard HRCT

\begin{tabular}{|l|c|c|c|c|}
\hline & $\begin{array}{c}\text { HCV negative IIP cases } \\
\mathbf{N = 2}\end{array}$ & $\begin{array}{c}\text { HCV positive cases } \\
\mathbf{N = 1 2}\end{array}$ & & P \\
\hline \multirow{2}{*}{$\begin{array}{l}\text { HRCT } \\
\text { Score }\end{array}$} & $0.5(0-1)$ & $3(2-4)$ & $\mathrm{Z}=2.278$ & $0.023^{*}$ \\
\cline { 2 - 5 } & $0.5 \pm 0.71$ & $2.92 \pm 0.79$ & $\mathrm{~T}=4.025$ & $0.002^{*}$ \\
\hline
\end{tabular}

Table (5): PCR results among HCV positive cases as regard IIP distribution

\begin{tabular}{|c|c|c|c|c|c|c|}
\hline \multirow{2}{*}{ HCV-PCR } & \multicolumn{2}{|c|}{$\begin{array}{c}\text { without IIP } \\
N=13\end{array}$} & \multicolumn{2}{|c|}{$\begin{array}{c}\text { With IIP } \\
\mathrm{N}=12\end{array}$} & \multirow[t]{2}{*}{$X^{2}$} & \multirow[t]{2}{*}{$\mathbf{P}$} \\
\hline & No & $\%$ & No & $\%$ & & \\
\hline Low viremia & 11 & $84.6 \%$ & 0 & $0 \%$ & \multirow{4}{*}{18.132} & \multirow{4}{*}{$<0.001 *$} \\
\hline Moderate viremia & 0 & $0 \%$ & 0 & $0 \%$ & & \\
\hline High viremia & 2 & $15.4 \%$ & 12 & $100 \%$ & & \\
\hline Very high viremia & 0 & $0 \%$ & 0 & $0 \%$ & & \\
\hline
\end{tabular}

Table (6): METAVIR score and IIP in HCV positive group

\begin{tabular}{|c|c|c|c|c|c|c|}
\hline \multirow{2}{*}{$\begin{array}{l}\text { METAVIR } \\
\text { score }\end{array}$} & \multicolumn{2}{|c|}{$\begin{array}{c}\text { without IIPs } \\
\mathrm{N}=13\end{array}$} & \multicolumn{2}{|c|}{$\begin{array}{c}\text { With IIPs } \\
\mathrm{N}=12\end{array}$} & $\mathbf{T}$ & $\mathbf{P}$ \\
\hline & No & $\%$ & No & $\%$ & \multirow{6}{*}{12.051} & \multirow{6}{*}{$0.002 *$} \\
\hline F0 & 0 & $0 \%$ & 0 & $0 \%$ & & \\
\hline F1 & 3 & $23.1 \%$ & 0 & $0 \%$ & & \\
\hline $\bar{F} 2$ & 7 & $53.8 \%$ & 1 & $8.3 \%$ & & \\
\hline$\overline{F 3}$ & 3 & $23.1 \%$ & 11 & $91.7 \%$ & & \\
\hline $\mathrm{F} 4$ & 0 & $0 \%$ & 0 & $0 \%$ & & \\
\hline
\end{tabular}

\section{DISCUSSION}

Hepatitis $\mathrm{C}$ virus (HCV) is a hepatotropic and lymphotropic Flavivirus virus with multiple hepatic and extrahepatic manifestations (EHM). Many previous studies have documented that 40$70 \%$ of chronic HCV patients will develop at least one of EHM throughout the course of the disease. EHM could be the first presenting illness of chronic HCV infection. Moreover, some patients develop EHM without any hepatic manifestations [3]. Both direct and indirect pulmonary involvement has been recorded in chronic HCV infections. Interstitial lung disease (ILD) is a suggested one of the direct pulmonary manifestations of chronic HCV infection [7-10].

Data about ILD from developing countries are lacking. In some countries the diagnosis of ILD can be mistaken with highly prevalent diseases such as tuberculosis which leads to fibrosis mimicking ILD. The Limited resources and poor socio-economic conditions adds to the problem [37]. This work aims at clarifying the exact relation between chronic HCV infection and ILD.

The study included 50 patients divided into 2 groups, chronic HCV positive (25 patients) and chronic HCV negative (25 patients) groups. Both groups were divided into age and sex groups without any significant difference in all demographic parameters.

Within HCV positive group, dyspnea and dyspnea score were found to be more in with IIPs patient than without IIPs patients and the difference was highly significant. However, Martinot-Peignoux et al. [26] found no clinical difference in HCV positive patients that can be attributed to the short duration of disease in their studied IPF 
patients with no chance to develop the full blown clinical picture of the pulmonary pathology.

Cirrhosis was delineated by the lower normal albumin level, low platelets count, minimal increase in bilirubin level and the more elevation of ALT than AST. Cirrhosis was excluded mainly by the liver biopsy.

Hypoxemia was more found among HCV positive group than $\mathrm{HCV}$ negative group and the difference was highly significant. This can be explained by the more prevalence of IPF among HCV positive group. IPF is involved in impairment of gas exchange and the eventual hypoxemia through chronic immune activation and inflammation induced by chronic HCV infection leading to decline in pulmonary functions. Our results coincide with those of Saleh et al. [27] who documented $\mathrm{HCV}$ positive related cryoglobulinemia that can be involved in impaired gas exchange and air way parameters. Hypoxemia was also encountered in patients without IPF that can be explained by the diffuse pulmonary vascular dilatation and aneurysmal formation leading to ventilation perfusion mismatching and eventual impaired pulmonary gas exchange. The restrictive pattern of pulmonary functions was the more prevalent in $\mathrm{HCV}$ positive than $\mathrm{HCV}$ negative patients and the difference was highly significant. This result coincides with that of Elham et al. [28] and can be explained in part by the ongoing interstitial pathology and also by the superadded polymyositis which is commonly encountered as a complication of chronic $\mathrm{HCV}$ infection. Polymyositis can impair the respiratory mechanism through weakening of respiratory muscles.

IPF cases were more prevalent among patients with high HCV viremia than other groups. Also, high viremia was more encountered in patients with IPP than without IPP and the difference was highly significant. This result agrees with that of Saleh et al. [27] who found an intimate relation between HCV viremia and the cryoglobulinemia involved in pulmonary interstitial pathology and the eventual impaired gas exchange. So, viremia may be implicated in IPF by directly pathogenic effect on lung parenchyma or indirectly through autoimmune mechanisms and cryoglobulinemia.

Our study showed that IIPs was more prevalent among HCV positive patients than HCV negative patients and the difference was highly significant. This result agrees with that of Ueda et al. [29] in a Japanese study- and Meleconi et al. [30] who found- in an Italian study- that IPF patients were positive for $\mathrm{HCV}$ - antibodies. $\mathrm{HCV}$ antibodies are suggested to have a role in the pathogenesis of IPF through lymphotropism which induces chronic immune activation and inflammation and eventual pulmonary fibrosis imitating that happening in the liver. Koike et al. [31] explained that by the accumulation of immunoglobulins and immune complexes in lung tissue due to passage of gut-derived antigens and antibodies via portal circulation to the lungs. On the other hand, Irving et al. [32] in a British study- found no significant relation between HCV and IPF. This controversy can be attributed to the difference in environmental and demographic parameters between the previous studies including the different susceptibilities to $\mathrm{HCV}$ infection. This also can be explained by whether the pathogenesis is directly induced by the virus or through cryoglobulinemia $[27,35]$. Moreover, the false positive rate of anti-HCV testing can play a role in this controversy [36].

According to METAVIR score, IIP was found to be more prevalent among F3 group while without IIP was more prevalent among F2 group and the difference was highly significant. This result coincides with that of Elnady et al. [33] who found direct correlation between liver fibrosis stages and HRCT of the studied patients. This can be explained by the potential alveolitis induced by $\mathrm{HCV}$ with eventual pulmonary fibrosis.

Higher HRCT scores was found among HCV positive IIP patients than $\mathrm{HCV}$ negative IIP patients by semi- quantitative scoring and the difference was highly significant. This result agrees with that of Rabae et al. [34] who found that HRCT score was higher among HCV positive IPF patients than HCV negative IPF patients. This can be attributed to the increased reticular fibrosis and honey- combing extending into the lung lobules in $\mathrm{HCV}$ positive cases than $\mathrm{HCV}$ negative cases. This pulmonary pathology imitates that induced by HCV in the liver. This pathology is related to the $\mathrm{HCV}$ lymphotropism with subsequent immune activation and inflammation.

\section{CONCLUSION}

ILD was frequently encountered in patients with chronic HCV infection with higher grades of fibrosis and hypoxemia. HCV infection may be a predisposing factor for IPF. 
Funding: None.

\section{Conflicts of interest: None.}

Ethical approval:Approved ; written consents have been taken from all included patients.

\section{REFERENCES}

1. Bonkovsky HL, Mehta S. Hepatitis C: a review and update. J Am Acad Dermatol. J Am Acad Dermatol 2001; 44(2):159-82.

2. Zignego AL, Brechot C. Extrahepatic manifestations of $\mathrm{HCV}$ infection: facts and controversies. J Hepatol. 1999; 31(2):369-76.

3. Cacoub P, Poynard T, Ghillani P, Charlotte F, Olivi M, Piette JC, Opolon P. Extrahepatic manifestations of chronic hepatitis C. MULTIVIRC Group. Multidepartment Virus C. Arthritis Rheum. 1999; 42(10):2204-12.

4. Kanazawa H, Mamoto T, Hirata K, Yoshikawa J. Interferon therapy induces the improvement of lung function by inhaled corticosteroid therapy in asthmatic patients with chronic hepatitis $\mathrm{C}$ virus infection: a preliminary study. Chest. 2003; 123(2):600-3. [PubMed]

5. Kanazawa H, Yoshikawa J. Accelerated decline in lung function and impaired reversibility with salbutamol in asthmatic patients with chronic hepatitis $\mathrm{C}$ virus infection: a 6-year follow-up study. Am J Med. 2004; 116(11):749-52.

6. Erol S, Saglam L, Ozbek A, Kadanali A. Hepatitis C Virus Infection and Chronic Obstructive Pulmonary Disease. Hepat Mon. 2009; 9(1):39-44.

7. Meliconi R, Andreone P, Fasano L, Galli S, Pacilli A, Miniero R, et al. Incidence of hepatitis $\mathrm{C}$ virus infection in Italian patients with idiopathic pulmonary fibrosis. Thorax. 1996; 51:315-317.

8. Ueda T, Ohta K, Suzuki N, Yamaguchi M, Hirai $\mathrm{K}$, Horiuchi $\mathrm{T}$, et al. Idiopathic pulmonary fibrosis and high prevalence of serum antibodies to hepatitis C virus. Am Rev Respir Dis. 1992; 146: 266-268.

9. Rasoul Aliannejad and Mostafa Ghane. Hepatitis $\mathrm{C}$ and pulmonary fibrosis. Hepat Mon. $2011 \mathrm{Feb}$ 1; 11(2): 71-73.

10. Segna D1, Dufour JF2. Other Extrahepatic Manifestations of Hepatitis C Virus Infection (Pulmonary, Idiopathic Thrombocytopenic Purpura, Nondiabetes Endocrine Disorders). Clin Liver Dis. 2017 Aug; 21(3):607-629.

11. Mandell MS, Groves BM. Pulmonary hypertension in chronic liver disease. Clin Chest Med. 1996; 17(1):17-33.

12. Krowka MJ, Dickson ER, Cortese DA. Hepatopulmonary syndrome. Clinical observations and lack of therapeutic response to somatostatin analogue. Chest. 1993; 104(2):515-21.
13. Manganelli P, Salaffi F, Subiaco S, Carotti M, Cervini C, Consigli G, et al. A. Bronchoalveolar lavage in mixed cryoglobulinaemia associated with hepatitis C virus. Br J Rheumatol. 1996; 35(10):978-82.

14. Aisa Y, Yokomori H, Kashiwagi K, Nagata S, Yanagisawa R, Takahashi M, et al. Polymyositis, pulmonary fibrosis and malignant lymphoma associated with hepatitis $\mathrm{C}$ virus infection. Intern Med. 2001; 40(11):1109-12.

15. Kornum JB, Christensen S, Grijota M, Pedersen L, Wogelius P, Beiderbeck A, et al. The incidence of interstitial lung disease 1995-2005: a Danish nationwide population-based study. BMC Pulm Med 2008; 8:24.

16. King TE, Jr., Pardo A, Selman M. Idiopathic pulmonary fibrosis. Lancet (London, Engl). 2011; 378(9807): 1949-61. Spectrum of interstitial lung disease from a tertiary care hospital in Karachi.

17. Sarwar Zubairi AB, Hassan M, Shahzad T, Sarwar S, Abbas A, Ahmad H, Irfan M. Spectrum of interstitial lung disease from a tertiary care hospital in Karachi. J Pak Med Assoc. 2017 Jul; 67(7):1065-1069.

18. Manns M, Marcellin P, Poordad F, de Araujo ES, Buti M, Horsmans Y, et al. Simeprevir with pegylated interferon alfa $2 \mathrm{a}$ or $2 \mathrm{~b}$ plus ribavirin in treatment-naive patients with chronic hepatitis $\mathrm{C}$ virus genotype 1 infection (QUEST-2): a randomised, double-blind, placebo-controlled phase 3 trial. Lancet. 2014 Aug 2; 384(9941):414-26.

19. American Thoracic Society/European Respiratory Society International Multidisciplinary Consensus Classification of the Idiopathic Interstitial Pneumonias. This Joint Statement of the American Thoracic Society (ATS), and the European Respiratory Society (ERS) was adopted by the ATS Board of Directors, June 2001 and by The ERS Executive Committee, June 2001.American Journal of Respiratory and Critical Care Medicine 2002. Vol. 165(2):277-304.

20. Demedts M, Costabel U. American Thoracic Society/European Respiratory Society (ATS/ERS) international multidisciplinary consensus classification of the idiopathic interstitial pneumonias. Eur Respir J 2002; 19: 794-796.

21. King TE. Idiopathic interstitial pneumonias: progress in classification, diagnosis, pathogenesis and management. Trans Am Clin Climatol Assoc 2004; 115: 43- 78 .

22. American Thoracic Society/European Respiratory Society International Multidisciplinary Consensus (ATS/ ERS). Update of the international Multidisciplinary Classification of the Idiopathic Interstitial Pneumonias. Am J Respir Crit Care Med 2013; 188: 733- 748 . 
23. Margaritopoulos G, Romaggnoli M, Poletti NM, Siafakas NM, Wells AU and Antoniou KM. Recent advances in the pathogenesis and clinical evaluation of pulmonary fibrosis. Eur Respir Rev 2015; 21:123, 48-56.

24. American Thoracic Society. Dyspnea Mechanisms, Assessment, and Management: A Consensus Statement. American Journal of Respiratory and Critical Care Medicine. 1999; 159(1): 321- 340.

25. Martin NK, Vickerman P, Foster GR, Hutchinson SJ, Goldberg DJ, Hichman M. Can antiviral therapy for hepatitis $\mathrm{C}$ reduce the prevalence of $\mathrm{HCV}$ among injecting drug user populations? A modeling analysis of its prevention utility. J Hepatol 2011; 54: 1137- 1144.

26. Martinot-Peignoux M, Boyer N, Cazals-Hatem D, Pham B N, GervaisA, Le Breton V, et al. Prospective study on anti -hepatitis $\mathrm{C}$ viruspositive patients with persistently normal serum alanine transaminase with and without detectable serum hepatitis C virus RNA. Hepatology 2001; 34: 1000- 1005.

27. Saleh AM, Elalfy H, Arafa MM, Abousamra N, El Badrawy A, Mohamed MA, et al. Association between $\mathrm{HCV}$ mixed cryoglobulinemia and pulmonary affection: the role of TNF- alpha in the pathogenesis of pulmonary changes. Egypt $J$ Chest Dis Tuberc 2014; 63:259- 265.

28. Elham A. Hassan, Mohamed O. Abdel Malek, Ali A. Hasan and Asmaa O. Ahmad. Does hepatitis C virus enhance prevalence of idiopathic pulmonary fibrosis and affect its severity? An Egyptian study. Egyptian Journal of Bronchology 2015; 9:69- 72

29. Ueda T, Ohta T, Suzuki N, Yamaguchi M, Hirai $\mathrm{K}$, Horiuchi $\mathrm{T}$, et al. Idiopathic pulmonary fibrosis and high prevalence of serum antibodies to hepatitis Cvirus. Am Rev Respir Dis.1992;146(1): 266-8.
30. Meleconi R, Andreone P, Fasano L, Galli S, Pacilli A, Miniero R, et al. Incidence of hepatitis $\mathrm{C}$ virus infection in Italian patients with idiopathic pulmonary fibrosis. Thorax 1996; 51:315- 317.

31. Koike K, Moriya K, Ishibashi K, Yotsuyanagi H, Shinatani Y, Fujie H, et al. Sialadenitis histologically resembling Sjogren syndrome in mice transgenic for hepatitis C virus envelop genes. Proc Natl Acad Sci USA. 1997; 94(1):233-6.

32. Irving WL, Day S, Johnston ID. Idiopathic pulmonary fibrosis and hepatitis $\mathrm{C}$ virus infection. Am Rev Respir Dis 1993; 148: 16831684.

33. Elnady M, Helmy N, Assal $\mathrm{H}$ et al. Interstitial pulmonary disease in hepatitis $\mathrm{C}$ virus patients. Chest 2011; 140(4- meeting abstract).

34. Rabea A, Zidan M, Daabis R, El Sayed P, Samir $\mathrm{S}$. Prevalence of chronic hepatitis $\mathrm{C}$ virus (HCV) infection in patients with idiopathic pulmonary fibrosis. Egyptian Journal of Chest Diseases and Tuberculosis. 2015; 64,907-913.

35. Ferri C, La Civita L, Fazzi P, Solfanelli S, Lombardini F, Begliomini E, et al. Interstitial lung fibrosis and rheumatic disorders in patients with hepatitis $\mathrm{C}$ virus infection. Br J Rheumatol 1997; 36(3):360-5.

36. Yasuji Arase, Fumitaka Suzuki, Yoshiyuki Suzuki, Norio Akuta, Masahiro Kobayashi, Yusuke Kawamura, et al. Hepatitis C virus enhances incidence of idiopathic pulmonary fibrosis. World J Gastroenterol. 2008 Oct 14; 14(38): 58805886.

37. Ali Bin Sarwar Zubairi, Maryam Hassan, Talha Shahzad, Sajjad Sarwar, Aamir Abbas, Huzaifa Ahmad, Muhammad Irfan. Spectrum of interstitial lung disease from a tertiary care hospital in Karachi. Journal of Pakistan Medical Association 2017; 67(7):1065- 1069. 